\title{
ESCRITAS FEMININAS NA CASA OITOCENTISTA: MEMÓRIAS SOBRE O DIÁRIO DA VISCONDESSA DE ARCOZELO
}

\author{
Maria Celi Chaves Vasconcelos ${ }^{1}$
}

\section{RESUMO}

O estudo tem como objetivo analisar o Diário de Lembranças da viscondessa de Arcozelo, buscando recompor os cenários onde ela realizava suas escritas pessoais. Em um plano específico, verifica-se como geria suas propriedades e seus pertences, além do que era esperado de uma mulher que foi educada para ser boa esposa e mãe. No que tange a aspectos metodológicos, são acessados dois tipos de fontes entrecruzadas: os registros anotados no Diário e as informações obtidas por meio de periódicos da época. Conclui-se que a casa oitocentista era o cenário da escrita, em seus aposentos mais herméticos, mantendo a representação do que era apropriado e permitido ao gênero feminino.

Palavras-chave: Escritas femininas, Diário de Lembranças, Viscondessa de Arcozelo, Casa oitocentista, Espaços domésticos.

${ }^{1}$ Universidade do Estado do Rio de Janeiro (UERJ), Rio de Janeiro/RJ, Brasil. 


\section{ESCRITOS FEMENINOS EN LA CASA OCHOCENTISTA: RECUERDOS SOBRE EL DIARIO DE LA VISCONDEZA DE ARCOZELO}

\section{RESUMEN}

El estudio tiene como objetivo analizar el Diario de Recuerdo de la vizcondesa de Arcozelo, buscando recomponer los escenarios dónde realizó sus escritos personales. En un plan específico, se verifica cómo gestionaba sus propiedades y sus pertenencias, además de lo que se esperaba de una mujer que fue criada para ser una buena esposa y madre. En lo que atañe a los aspectos metodológicos, se accede a dos tipos de fuentes entrecruzadas, los registros anotados en el Diario y la información obtenida mediante periódicos de la época. Se concluye que la casa del ochocientos era el escenario de la escritura en sus salas más herméticas, manteniendo la representación de lo apropiado y permitido al género femenino.

Palabras clave: Escritos femeninos, Diario de recuerdo, Vizcondesa de Arcozelo, Casa ochocentista, Espacios domésticos.

\section{FEMALE WRITINGS IN A NINETEENTH CENTURY HOUSE: MEMORIES ABOUT VISCONDESS OF ARCOZELO'S DIARY}

\section{ABSTRACT}

The study aims to analyze the viscountess of Arcozelo's Diary of Remembrance, seeking to recompose the scenarios in which she performed her personal writings. In a specific plan, we verify how she managed her properties and his belongings, beyond what was expected from a woman who was raised to be a good wife and mother. In respect to methodological aspects, we accessed two types of cross-linked sources, the records noted in the Diary and information obtained through journals of the time. We have concluded that the nineteenth century house was the scenario of writing in its most hermetic rooms, maintaining the representation of what was appropriate and allowed to the female gender.

Keywords: Feminine writings, Remembrance Diary, Viscountess of Arcozelo, Nineteenth century house, Domestic spaces.

\section{ÉCRITURES FÉMININES DANS LA MAISON DU XIX SIÈCLE: DES MÉMOIRES SUR LE JOURNAL DE LA VICOMTESSE D'ARCOZELO}

\section{RÉSUMÉ}

L'étude a pour objectif d'analyser le Journal du Souvenir de la vicomtesse d'Arcozelo, en train de recomposer les scénarios dans lesquels elle a écrit ses documents écrits personnelles. Dans un plan spécifique, il est vérifié comment elle a géré ses propriétés et ses biens, en plus de ce qui était attendu d'une femme élevée pour être une bonne épouse et une mère. En ce qui concerne les aspects méthodologiques, on accède à deux types de sources entrecroisés: les enregistrements qui elle a noté dans son Journal et les informations obtenues par de journaux 
périodiques de l'époque. Il est conclu que la maison du XIXe siècle était le lieu d'écriture dans ses salles les plus hermétiques, préservant la représentation de ce qui était approprié et autorisé au genre féminin.

Mots-clés: Écrits féminins, Journal du souvenir, Vicomtesse d'Arcozelo, La maison du XIXe siècle, Espaces domestiques. 


\section{A HISTÓRIA DA PESQUISA: UM DIÁRIO, UM ANO, UMA MULHER, TRÊS FAZENDAS DE CAFÉ}

O presente artigo tem como foco evidenciar o lugar de elaboração de escritas íntimas femininas, a casa, onde, na segunda metade do século XIX, as mulheres, em seus espaços "privados" e domésticos, realizavam a escrita de cartas, diários, bilhetes, faziam anotações em livros, os quais lhes eram permitidos ler, colecionavam álbuns de poesias, entre outras atividades dessa natureza.

Mas não se tratava de quaisquer mulheres. Eram aquelas que sabiam ler e escrever, condições raramente estendidas para além das camadas da população mais favorecidas economicamente, já que, segundo Bolmann (2011a, p. 28), a capacidade de ler propiciava "no plano íntimo e pessoal, o desenvolvimento de novos modelos de comportamento que, com o tempo, iriam corroer a legitimidade da autoridade estabelecida, tanto no âmbito espiritual como temporal”. De acordo com o autor (BOLMANN, 2011b, p.10), a leitura e a escrita, nos anos de 1800, eram atividades consideradas tão "perigosas" para as mulheres, que praticadas quase em segredo, de forma, preferencialmente, reclusa.

As mulheres que liam e escreviam no Brasil do século XIX, além de apresentarem um diferencial social, faziam-no sob condições bastante determinadas, em suas casas, normalmente enclausuradas em seus aposentos e conscientes da vigilância a que estavam submetidas, tanto a masculina (de pais, maridos, irmãos) quanto à feminina (de mães, tias, avós e outras agregadas que compunham a extensa parentela que habitava as casas).

No âmbito em foco nesta pesquisa, a casa que se coloca em evidência é, particularmente, uma entre as tantas propriedades senhoriais características da zona urbana - a Corte do Império brasileiro - e da zona rural - as casas-sede das grandes fazendas de café do interior da Província do Rio de Janeiro.

É nesse contexto que encontramos uma dessas escritoras, a viscondessa 
de Arcozelo, nascida Maria Isabel de Lacerda Werneck, filha do barão de Paty do Alferes, um dos mais representativos fazendeiros do café de seu tempo, mulher aristocrata que "viveu o apogeu do Império do Brasil, bem como a sua decadência" (VASCONCELOS, 2014, p.95), deixando registrado um ano de sua vida, 1887, em um egodocumento extremamente singular, por sua autoria e contexto, o Diário de Lembranças (1887) ${ }^{2}$. O título de visconde de Arcozelo foi concedido a seu marido, Joaquim Teixeira de Castro, em 1874, pelo Rei de Portugal, D. Luis I, referindo-se à vila onde o visconde nasceu. Desde então, a viscondessa passou a usar somente o título como a sua designação pessoal (CASTRO, 2004).

O Diário de Maria Isabel, datado de 1887, é escrito durante os períodos em que ela está em suas três fazendas de café, Fazenda Monte Alegre, Fazenda Piedade e Fazenda Freguesia.Também há registros realizados em sua casa na Corte, quando passa alguns dias nela, bem como no decorrer de sua estada em Caxambu, na temporada anual em que desfruta de uma "estação de águas termais" (VASCONCELOS, 2015).

O estudo do Diário de Lembranças da viscondessa de Arcozelo permite, por meio de suas anotações, confrontar resquícios do passado no presente, notadamente no que se refere às suas moradias, ou aos lugares onde ela permaneceu por mais tempo ao longo do ano de 1887. No entanto, os vestígios contidos na escrita cotidiana da viscondessa em relação às suas casas, a quem vivia nelas, às suas visitas, ao modo como estavam organizadas suas propriedades e aos pertences que mais lhe apeteciam listar não são suficientes para recriar o cenário em que a protagonista realizava sua escrita íntima. Isso porque apenas a luminosidade do sol que entra pelas janelas (ainda originais) nos aposentos que lhe pertenceram pode aspirar ser a mesma, no que se refere à recomposição do real e do vivido, porquanto todas as outras tentativas de

\footnotetext{
${ }^{2} \mathrm{O}$ Diário de Lembranças pertence ao acervo do Museu Imperial em Petrópolis, doado a essa Instituição por Ligia Werneck de Castro Souza Marques, neta da viscondessa, em 26 de dezembro de 1994, conforme registrado no documento de doação e anotado no livro de memórias escrito por Maria Werneck de Castro (2004).
} 
recriação possuam lacunas produzidas por tempos dissonantes entre o passado e o presente.

Ainda assim, certamente, era no ambiente doméstico que se produziam as escritas íntimas femininas, tivessem elas interlocutores ou não. No caso do Diário da viscondessa de Arcozelo, o ritual de sua produção estava imerso em um cenário que guardava estreita relação com os aposentos e com o seu mobiliário, com o horário de elaboração, com a materialidade dos objetos usados, com a forma e com o conteúdo daquilo que se pretendia registrar.

Schettino e Lemos (2014, p.320), em pesquisa que relaciona o papel social feminino e as transformações da arquitetura residencial no final do século XIX, no Rio de Janeiro, evidenciam que a relação entre a mulher e a casa "é uma construção cultural e histórica", iniciada no século XVIII e consolidada pela burguesia ascendente do século XIX, para a qual as funções de esposa, mãe e dona-de-casa deviam ser as aspirações principais para a preservação da família e da sociedade. "O espaço privado passou a ser definido como um lugar essencialmente feminino", o símbolo da virtude, enquanto a rua era um lugar exclusivo para o trânsito masculino. Portanto, "nada mais natural do que pensar que o espaço habitacional poderia ser planejado em favor da prática das atividades domésticas e do conforto da mulher que ali passava a maior parte da sua vida" (SCHETTINO \& LEMOS, 2014, p. 320).

Nessa perspectiva, o objeto do estudo em pauta é a casa como o local de produção de escritas íntimas femininas, considerando a sua centralidade para a mulher na cena oitocentista, uma vez que a vida se concentrava no interior de suas edificações, desde o nascimento até os rituais de morte, particularmente daquelas que pertenciam às camadas mais abastadas da população.

Em um plano mais geral, elege-se a casa e o protagonismo de sua dona - a viscondessa de Arcozelo-, como objetivo central do estudo, a fim de evidenciar o lugar onde ela realizava suas escritas. De forma mais específica, emergem também registros cotidianos anotados no Diário de Lembranças, a partir dos quais é possível analisar o modo como a viscondessa geria suas 
propriedades e seus pertences; além de verificar o que era esperado de uma mulher que foi educada, conforme os manuais de sua época, para ser uma boa esposa e mãe, bem como capaz de administrar os espaços domésticos.

No que tange aos procedimentos metodológicos, diante de um egodocumento raro, o Diário de Lembranças da viscondessa de Arcozelo, optouse por trabalhar o conteúdo, caracterizado como uma "escrita íntima", sob dois aspectos entrecruzados: a viscondessa como uma mulher representante da condição feminina de seu tempo e da camada social a qual pertencia, revelada pelas informações do Diário; e essas mesmas informações confrontadas a outras obtidas por meio de periódicos da época, com o propósito de demonstrar os cenários em que a viscondessa escrevia, destacando-se a existência, a organização, a mobília e a decoração dos espaços domésticos utilizados por ela para essa finalidade.

Cabe ressaltar, ainda, a realização de visita a algumas das propriedades que pertenceram à viscondessa, com o intuito de averiguar o que restava dessas edificações para além das memórias imateriais. O autor Bill Bryson (2011), ao adquirir uma casa que remonta, em suas primeiras fundações, ao medievo, vai, a partir da configuração arquitetônica da moradia, investigar aspectos da vida privada e da organização dos ambientes, buscando respostas de como estavam distribuídos móveis, decorações e utensílios domésticos, em fontes que incluem narrativas e escritas pessoais, que descrevem a habitação em cada época de sua ocupação, analisando os costumes, os sentidos e as sensibilidades de seus moradores.

Para contar parte da história da viscondessa, particularmente o cenário que a envolvia na produção de suas escritas íntimas, fiz um caminho inicial inverso daquele do autor, partindo do Diário de Lembranças, a fim de buscar anotações sobre as casas às quais a autora se refere para, em seguida, confrontálas às informações veiculadas pelos periódicos da época. 


\section{A ESCRITA COMO TESTEMUNHA: O DIÁRIO, A VISCONDESSA E O VISCONDE}

"O que é importante na vida de uma pessoa e o que não é? A partir do que apreciá-la e como dar conta dela?” Como tentar contar uma vida sem cair na ilusão de recompô-la, como foi vivida, mesmo que por meio do testemunho de escritas íntimas? Essas são algumas das questões que Sabrina Loriga propõe no livro $O$ pequeno $X$ da biografia à história (2011). Para a autora, "reconstituir a origem e evolução de um acontecimento é impossível" (LORIGA, 2011, p.194), ainda que se possa debruçar sobre fragmentos de uma experiência, registros de testemunhos etc. Isso porque a análise incorpora elementos posteriores, que se originam do presente e não do fato em si. Portanto, ao esquadrinhar arquivos pessoais, cartas, diários, a narrativa já é encaminhada para a busca de explicações, na contemporaneidade, do que ocorreu no passado, distanciandose totalmente do momento em que aconteceu, no qual não se podia supor o desfecho final. Assim, "a noção de verdade histórica é [sempre] torturada pela dúvida” (LORIGA, 2011, p. 229).

O Diário de Lembranças pertencente à viscondessa de Arcozelo corresponde a um "caderno" de capa dura, no formato e tamanho de uma agenda de mesa moderna, com uma encadernação verde, decorada com papel marmorizado de tons bege e marrom. Na capa, destaca-se uma etiqueta com a ponta dobrada, em que se lê: "A. Brandão", nome abreviado do editor da publicação, Antônio José Gomes Brandão. Centralizado, encontra-se o título “DIÁRIO DE LEMBRANÇAS". Abaixo, em meio a arabescos, consta a data: 1887 (VASCONCELOS, 2014; 2015).

Sua apresentação, após mais de 130 anos da edição, ainda é capaz de denotar a elegância e o estilo em voga na época, o que fazia da publicação, provavelmente, um objeto de luxo, acessível a poucas pessoas. A contracapa trazia a folhinha para o primeiro semestre do ano de 1887 , as fases da lua e os santos padroeiros de cada dia, sendo indicado que o segundo semestre estava no final do livro. Antônio Gomes Brandão informava ainda que o livro era 
produzido em sua tipografia, que ficava situada na Rua da Quitanda, número 90, e se referia a si próprio como um “comerciante de papel e de livros”.

A viscondessa escreve todos os dias do ano, com raras páginas sem registros, não obstante o Diário ter chegado aos dias atuais com os espaços em branco, restantes de algumas folhas, recortados ou aproveitados para anotações posteriores. Há também poucas páginas em que ela escreve "nada de novo", demonstrando que, mesmo para informar não ter o que contar, abria cotidianamente o Diário.

Como ressalta Lejeune (1997), é preciso estar atento aos padrões que a autora usa. Muito embora o seu Diário seja caracterizado como de crônicas, fixando-se nos acontecimentos externos da vida cotidiana, a viscondessa utiliza um padrão permanente de anotações, especialmente com a elaboração de listas, cuja leitura oferece elementos para a reconstrução de seu dia a dia de mulher letrada e dona de fazendas de café no oitocentos. Os escritos permitem, ainda, entrever suas relações familiares, as amizades, as redes de sociabilidade, a organização das casas, as despesas, a relação com os escravos, com a morte, com as doenças, enfim a proximidade e o distanciamento com as marcas cotidianas da época e do lugar em que vivia.

No entanto, para chegar às escritas pessoais da viscondessa, no ano de 1887, é preciso localizá-la no protagonismo do seu tempo e do seu contexto, que lhe permitiam escrever durante um ano inteiro com preocupações que se referiam, notadamente, à preservação de sua riqueza por meio das condições climáticas favoráveis ao plantio e à colheita do café, aos cuidados com a sua família e com a manutenção de seus escravizados, à listagem de seus pertences, às suas dívidas e aos seus devedores, a encomendas e a pequenas aquisições cotidianas, bem como à consolidação de laços de parentesco e de amizade, estreitando a rede de "iguais" que envolvia o seu entorno.

Além disso, as demonstrações de passividade que transparecem na sua escrita, diante de um cotidiano assolado por tempestades, doenças, mortes, acidentes e roubos, ocorrem, entre outras razões, porque a viscondessa era uma 
mulher casada que, antes de tudo, obedecia ao marido, mesmo que discordasse da sua opinião, o que raramente registra no Diário. De acordo com Mello (2019, p.328), “a família patriarcal era, sobretudo, o produto de uma concepção autoritária da natureza das relações entre os seus membros”.

À mulher, cabia submeter-se ao marido; e a viscondessa era casada com um dos mais representativos nobres e "capitalistas"3 da região de Vassouras, com grande atuação na Corte do Império brasileiro, ao longo das últimas décadas do século XIX. Embora não seja possível localizar uma única referência sobre a viscondessa nos periódicos contemporâneos à vida do casal, excetuando-se o obituário, corrobora-se o que afirma Perrot (2005, p. 11) sobre as mulheres: "fala-se pouco delas e ainda menos caso quem faça o relato seja um homem”. Em relação ao visconde de Arcozelo, há inúmeras informações, tendo em vista que ele, além de aristocrata e grande proprietário rural, era detentor de distintos cargos de importância econômica e social e, acima de tudo, de status naquela sociedade, estando constantemente mencionado nas páginas dos jornais da Corte e da sua região.

Portanto, para buscar a viscondessa, tornou-se fundamental encontrar o visconde, uma vez que ela estava à sua sombra, no silêncio, ao seu lado, invisibilizada, cuja postura, normalmente, era a de escuta, de espera: "o guardar as palavras no fundo de si” mesma e, às vezes, para o Diário. “Aceitar, conformar-se, obedecer, submeter-se e calar-se" são posições que podem ser depreendidas na escrita cotidiana do Diário de Maria Isabel (PERROT, 2005, p. 10).

Perrot (2005) chama a atenção para o fato de que "os arquivos privados conservados nos grandes depósitos públicos são quase exclusivamente os dos 'grandes homens" (PERROT, 2005, p. 10, grifo da autora), categoria na qual o visconde pode ser incluído quando se trata das últimas décadas do Império do Brasil. Os jornais de grande tiragem na Corte carioca, como o Jornal do Commercio e a Gazeta de Notícias (particularmente na década em que Maria 
Isabel escreve o seu Diário, os anos de 1880 a 1890), registram, em suas páginas, ao longo desse período, os vários cargos ocupados e as diversas funções desempenhadas pelo visconde. Consta, entre esses registros, que ele era sócio fundador, presidente e membro da diretoria da Caixa de Socorros de D. Pedro $V$; que participava do conselho fiscal da Companhia Brazileira de Electricidade; que foi o primeiro diretor e sócio da Companhia Ensacadora de Café ${ }^{4}$, diretor tesoureiro da Companhia Lavoura e Viação Fluminense e, ainda, diretor vicepresidente da Companhia Promotora de Industrias e Melhoramentos. Também compôs o conselho fiscal da Companhia Brazil Territorial e concorreu para a participação no consórcio de construção da Estrada de Ferro Victória, ligando essa cidade do Espírito Santo até Natividade na fronteira de Minas Gerais. Atuou, ainda, como sócio benemérito da Sociedade Propagadora das BellasArtes e como conselheiro da Sociedade Portugueza de Beneficência. Além disso, participou do conselho do Banco do Brasil e Londres, e foi o primeiro diretor da União - Associação de Seguros Mútuos sobre vida de Escravos, entre outras atividades no Município Neutro da Corte, no Município de Vassouras e na Freguesia de Paty de Alferes, da qual era eleitor alistado.

Em contraponto a essas ocupações que povoavam os jornais com propagandas, homenagens e agradecimentos, o visconde também se dedicava a outras atividades não tão prestigiosas, como por exemplo, a construção de "cortiços", assim denominados pela Gazeta de Notícias, em 5 de janeiro de 1887. Tratava-se das construções que o visconde mandou levantar na Rua da Relação e na Rua dos Inválidos, embargadas pelo fiscal da Câmara Municipal, como noticiava o periódico, mas que continuavam a ser edificadas a despeito da autoridade da Inspectoria Geral de Hygiene, e para as quais ele pretendia que se desse numeração. Em 27 de dezembro de 1887, o Jornal do Commercio, mais favorável ao visconde, informava que, com a interferência dos vereadores José do Patrocínio e Torquato Couto, havia-se dado numeração para os seus cinco prédios da Rua dos Inválidos e para um da Rua da Relação. Lograva êxito o

\footnotetext{
${ }^{4} \mathrm{Na}$ Ata da reunião dos sócios, datada de 4 de novembro de 1890 , lê-se a aprovação para a denominação de Sociedade Bancária Agrícola do Brazil, portanto, transformada em um Banco.
} 
visconde em numerar suas construções para serem alugadas, embora sob os protestos da Gazeta de Notícias, que em uma matéria jocosa, intitulada Bellezas Municipaes, demonstrava o desprezo do aristocrata à autoridade que não conseguiu alterar os planos privados em detrimento da ordem pública (GAZETA DE NOTÍCIAS, 05/01/1887).

O visconde também emprestava dinheiro com a garantia da penhora de bens e, assim, capitalizava inúmeros devedores, alguns ilustres, como o conde d’Eu, cuja dívida terminou por ser relaxada em termos de conciliação, como anotado no Jornal do Commercio, em 12 de fevereiro de 1890. Outros, entretanto, não tinham a mesma sorte do príncipe e viam a extensa lista de seus bens pessoais, desde "duas mesas de pinho envernizadas até oito quadros com paisagem e moldura dourada", serem anunciados a "pregão" pelo jornal, penhorados pelo visconde.

O dr. Edmundo Muniz Barreto, juiz substituto da $1^{\mathrm{a}}$ vara cível na capital federal da República dos Estados Unidos do Brasil: Faz saber aos que o presente edital de praça com o prazo de 10 dias virem, que o porteiro dos auditórios trará a público pregão de venda e arrematação os bens abaixo, penhorados pelo Visconde de Arcozello a D. Maria Stoffel e se achão avaliados na quantia de $74 \$$ e vão à praça no dia 8 de Abril do corrente ano (JORNAL DO COMMMERCIO, 08/04/1890).

As dívidas não pagas ao visconde podiam ser ainda de um montante muito maior, chegando a envolver toda a fortuna de uma família, como as terras das fazendas, dezenas de escravizados, as instalações e os moinhos, os animais e a produção existente, até os mais ínfimos pertences. É, por exemplo, um anúncio desse tipo que ocupa toda uma coluna no Jornal do Commercio, do dia 25 de outubro de 1879, no Edital publicado pelo juiz municipal de Vassouras, no qual o visconde solicita a execução da penhora dos bens do tenente-coronel Gil Francisco Xavier e de sua mulher, dando a impressão da completa ruína de seu devedor.

Enquanto isso, Maria Isabel cuida dos filhos, da casa, e escreve, 
provavelmente, outros diários, considerando o que Antônio Gomes Brandão informa na edição do seu Diário de Lembranças de 1887, que há quatro anos ininterruptos fazia essa publicação (VASCONCELOS, 2015). É possível que outros exemplares, ou até mesmo cartas, bilhetes, álbuns tenham sido confeccionados pela autora. No entanto, como assinala Perrot (2005, p. 10), "as mulheres são feitas para esconder a sua vida, na sombra do gineceu, do convento ou da casa”. Assim, se estes existiram, foram descartados, por não serem considerados como escritos relevantes. Não obstante, ao se descartar a escrita feminina, não chegaram até os nossos dias, especialmente, egodocumentos que poderiam oferecer testemunhos importantes para a recomposição de uma vida e de uma época, desprovidos das aspirações e das pretensões dos documentos públicos.

\section{A CASA E A SUA DONA: REGISTROS DE CENÁRIOS E DE BENS FEMININOS}

Em 1835, Martins (2009, p.74) anota: "há, em Valença e Vassouras, fazendas de 500 mil a 800 mil cafeeiros”. Em 1840, seguem para a exportação no porto do Rio de Janeiro "3 milhões e 463 mil sacas”. Esses números colocavam o país como o principal produtor de café do mundo e, progressivamente, essa riqueza passa a ser sentida nos hábitos tipicamente franceses que as elites adotam, a partir do acesso proporcionado pelo chamado “ouro negro". Schettino e Lemos (2014, p. 327) configuram melhor esse contexto:

A elite agrária enriquecida passou a adotar costumes tipicamente franceses incluindo, não somente expressões verbais, etiqueta social e moda, mas também a decoração e o luxo característico da França do século XIX. O aumento das importações nesse período demonstra o alto consumo dos produtos considerados de luxo que iam desde utensílios domésticos, passando pelos objetos de decoração até alimentos. 
A viscondessa de Arcozelo, descrita pela neta (CASTRO, 2004, p. 70) como uma mulher "herdeira do riquíssimo barão de Paty do Alferes“, possuía, além das três fazendas, numerosos outros bens, inclusive escravizados. Seu nascimento ocorre em 1840, no período áureo da produção cafeeira do seu tempo e do seu lugar e, portanto, sua casa e seus pertences, anotados no Diário, são um reflexo bastante significativo de como essa elite agrária forjou um modelo de propriedade senhorial, cujo espaço doméstico era gerido por sua dona, que acompanhava a prosperidade obtida com o café. Esse modelo era francês e cabia à dona da casa conhecê-lo e buscar acompanhá-lo.

Ao longo de todo o século XIX e início do XX, as mulheres da elite foram responsáveis pelo funcionamento da casa, o que não poderia ser considerada uma tarefa simples visto o tamanho das residências, o número de funcionários domésticos, o abastecimento e a preparação dos alimentos, o cuidado com os homens, as crianças e os convidados. Além da administração doméstica, as mulheres eram as figuras principais na alta sociedade, todas as atividades sociais da elite requeriam a presença feminina. Seu comportamento, roupas e joias nos eventos eram indicadores do status familiar (SCHETTINO \& LEMOS, 2014, p. 325).

Ainda que o Diário de Lembranças de Maria Isabel não contenha nada que possa indicar uma vida faustuosa, ou mesmo condizente com as posses do marido, assim como com a sua renda estampada nos jornais por meio das participações acionárias das companhias de que ele era sócio, sua posição econômica pode ser demonstrada na quantidade de pessoas que recebia e que fazia questão de convidar para almoçar e jantar, dar hospedagem e acomodar, da melhor maneira possível, em suas propriedades.

As autoras Mauad e Muaze (2004, p. 203), em estudo sobre o Diário de Lembranças, assinalam que as impressões registradas pela viscondessa, "nas quais se desvenda o cotidiano da aristocracia brasileira", são "bem menos" glamorosas do que o relato de "festas e do luxo de ocasiões especiais", notadamente aquelas contadas por viajantes que vivenciaram essas experiências 
em salões da Corte, ou mesmo nas recepções a personagens ilustres, como o próprio imperador, nas fazendas do interior. Contudo, a circulação permanente de pessoas nas fazendas "obrigava a um reabastecimento constante" (MAUAD e MUAZE, 2004, p. 206). Para tanto, fazia-se necessário dispor de grande quantidade de gêneros alimentícios de toda a ordem, que, embora anotados detalhadamente pela viscondessa, não pareciam fazer diferença no orçamento geral, mas muito pelo contrário, há menções de desagrado no Diário, quando um ou outro conviva decide não ficar para uma das refeições ou para pernoitar. Assim, era como se o luxo e a nobreza fossem também entendidos como representação de fartura e de boa recepção e acolhida, para além da coqueteria francesa.

No que se refere a um dos principais focos de investigação deste estudo, o cenário de produção da escrita íntima de Maria Isabel, o Diário contém referências a suas propriedades, à distribuição e à organização de sua casa, ao funcionamento de seu cotidiano e aos objetos de utilização doméstica.

A casa foi sempre um local de refúgio do indivíduo e da família, com importante função de representação, seja pela sua localização, seja por suas características construtivas. Os dispositivos escolhidos para uma determinada solução espacial determinam certo modo de relações interpessoais, mas também de relações econômicas (trabalho e produção nos espaços domésticos) e sociais mais largas (SANTOS, 2014, p. 209).

Em 12 de janeiro de 1887, a viscondessa de Arcozelo, em duas frases, apresenta os principais personagens e os locais que vão frequentar as páginas de seu Diário ao longo de todo o ano: "Depois do almoço partimos para a Freguesia para passarmos uns dias. Alzira, Francisquinho, Mario e Raul vierão a cavalo. Eu D. Sara e o Castro viemos de Troll” (DIÁRIO DE LEMBRANÇAS, 1887, 12/o1). Nesse excerto, ela registra a companhia da nora e dos três filhos, além da preceptora dos mais novos, Mario e Raul, e do visconde, a quem trata por “Castro”. Também indica a sua principal moradia, a Fazenda Monte Alegre, de 
onde parte para a Fazenda Freguesia, local em que escreverá nos próximos dias. Com relação à Monte Alegre, a neta Maria Werneck (CASTRO, 2004, p.109), assinala: "Naquela altura, Monte Alegre era a fazenda predileta, mas as duas outras, próximas, Piedade e Freguesia (depois chamada Arcozelo) eram bem equipadas, embora não com o mesmo requinte”.

É em Monte Alegre que a viscondessa realiza uma boa parte de suas anotações, recebe inúmeros visitantes para almoçar, para jantar e para pernoitar. É também o lugar em que guarda, registra, lista e confere os objetos que compõem a sua casa. Em 22 de dezembro, menciona o recebimento de 39 caixas de sabão, "faltando alguns tijolos em algumas caixas", e dois barris de vinho. A alusão feita a esse detalhe singular deixa antever a sua forma de administrar as propriedades, considerando que separa 20 caixas de sabão para o gasto, possivelmente, das casas, assim como um barril de vinho para o mesmo fim; e o restante, 19 caixas, registra como: “o mais é meu”.

Em relação aos seus pertences, escreve, em 9 de maio, que enviou Antoninho à cidade para fazer "compras", cujas despesas de viagem importaram em nove mil réis. Entre as compras, estão listados três bules, um leque, papel e lápis, suspensórios e grampos, chinelos e sapatos e três conchas.

Ainda que seu cotidiano, nas páginas do Diário, pareça bastante rústico, distanciando-se dos padrões franceses aspirados pela sociedade oitocentista (GAGLIARDO, 2014), por vezes, algumas referências denotam a sofisticação em meio à labuta da produção cafeeira. Em sua escrita, datada de 2 de agosto, a viscondessa declara que possui doze copos para água, "sendo dois de pés", e onze cálices, "sendo dois ordinários". Quanto à louça em serviço, lista três cálices para licor, seis pratos para ensopados, trinta pratos rasos, dois pratos para servir feijão, doze pratos fundos, dois pratos fruteiras, dezoito pratos pequenos, nove pratos listados, oito travessas, duas sopeiras, um prato para pão-de-ló, dois para amêndoas, uma saladeira e um prato para molho. Mesmo que possa se tratar apenas da louça em uso cotidiano, sugerindo haver outros aparelhos de jantar guardados nas amplas cristaleiras, as peças assinaladas 
parecem insuficientes para alguém que anota, em 14 de fevereiro de 1887: "jantarão aqui em casa entre os de casa e os de fora 30 pessoas".

Com relação à sua vida na Fazenda Monte Alegre, chama atenção a escrita do dia 15 de novembro, quando relata: às " 3 horas da madrugada senti bater no soalho, mandei abrir a janella e ver o que era”. Para uma casa que tinha dimensões amplas, dois andares, e os aposentos do casal ficavam localizados no segundo piso $^{5}$, é bastante interessante que a viscondessa tenha ouvido um barulho no "soalho", provavelmente da porta do andar térreo, para que desse a ordem de abrir a janela e identificar o visitante. Além disso, percebe-se que o visconde não estava, porque é ela quem dá a ordem e é atendida. Tal situação demonstra que costumava estar atenta a tudo o que se passava à sua volta, mesmo que uma visita inesperada, no meio da madrugada, denunciada apenas pelo barulho do assoalho ouvido de um quarto situado no canto direito da casa, ocupando uma parte nobre do segundo piso.

Mas é pelo Jornal do Commercio que o registro de uma circunstância singular permite a recomposição mais detalhada de um dos cenários de escrita da viscondessa. Em 16 de junho de 1883, a seguinte nota "social", intitulada “Despedida”, é assim publicada:

O Visconde de Arcozello, partindo hontem para a Europa no vapor Congo, e não tendo tempo para despedir-se de todos os seus amigos o fez por este meio, oferecendo-lhes seus préstimos em qualquer parte em que se achar. Rio de Janeiro, 16 de Junho de 1883 (JORNAL DO COMMERCIO, 16/06/1883).

Acompanhando o visconde, estava um filho, conforme a lista de

\footnotetext{
${ }^{5}$ Conforme Inventário das Fazendas do Vale do Paraíba Fluminense: "Internamente, a casa conta no pavimento térreo com um vestíbulo ladeado por alguns cômodos que funcionam como depósito, escritório e estar, além de uma grande sala de jogos. A escada interna de acesso ao pavimento superior também se localiza no vestíbulo, levando a uma sala de estar no segundo andar, tendo, à sua direita, uma ala íntima e, à esquerda, a ala de serviços. Aos fundos está a sala de jantar, que possibilita o acesso à cozinha, a varanda e a parte externa dos fundos desta edificação".

Disponível em: http://www.institutocidadeviva.org.br/inventarios/
} 
passageiros para Lisboa, da qual não constava o nome de Maria Isabel, que, presumivelmente, havia ficado na Fazenda Monte Alegre, enquanto o marido levava o rapaz para estudar na Europa. Naquele período, últimas décadas do oitocentos, como registram os jornais, quando as famílias viajavam para o "estrangeiro", era comum fecharem suas residências na Corte e se desfazerem de todos os móveis e utensílios por meio de leilões anunciados cotidianamente.

Com o visconde não foi diferente. Por diversos dias subsequentes à sua partida para a Europa, foi publicado por A. Cibrão ${ }^{6}$, leiloeiro famoso da época, o seguinte anúncio:

Autorizado pelo Exm. Sr. Visconde de Arcozello, que se retirou para a Europa faz leilão de toda a linda mobília espelhos e pinturas. Cortinas e reposteiros. Serviços de prata. Ditos de christofle. Ornamentos. Carros e arreios. Bilhar e pertenças, o que tudo servia ao uso deste distincto cavalheiro em sua residência Rua de D. Luiza, Hoje quartafeira, 27 do corrente, as 3 e $1 / 2$ horas. O catálogo que se segue tudo explica (JORNAL DO COMMERCIO, 27/06/1883).

Não é possível determinar com exatidão as razões que levaram o visconde e a viscondessa à decisão de leiloarem todos os objetos da casa localizada na rua D. Luíza ${ }^{7}$. Entretanto, constata-se que essa era uma prática das famílias que se retiravam durante algum tempo para a Europa, ou que se ausentavam no decurso de determinado período da Corte no Rio de Janeiro.

O Rio de Janeiro oitocentista, como cidade capital do Império e da República, lidava com uma mobilidade significativa de população residente. As idas e vindas de famílias de origens diversas, brasileiras ou estrangeiras, promoviam a necessidade frequente de aquisição e de descarte dos trastes que preenchiam as casas. Praticamente todos os

\footnotetext{
6 De acordo com Malta (2014, p.565), A. Cibrão foi um dos mais destacados leiloeiros da Corte até a década de 1880, "a partir do momento em que Affonso Nunes, J. Dias e Assis Carneiro imperaram até o final do século".

7 A Rua D. Luíza era, na metade do século XIX, o caminho de acesso de carruagens ao bairro de Santa Teresa. Na década de 1880 , tratava-se de uma rua com casas e chácaras, bastante apreciada pela aristocracia carioca. Atualmente, denomina-se Rua Cândido Mendes.
} 
dias, móveis eram comprados e vendidos. [...] A forma mais corrente de se desfazer dos trastes da casa se dava por meio de leilões, cujas ofertas eram publicadas diariamente nos jornais locais. Para aqueles que partiam para outras terras, mudando-se de cidade ou de país, ou por falecimento, o artifício dos leilões era um meio usual para se desfazer da maioria dos bens, móveis ou imóveis (MALTA, 2014, p. 562-563).

O leiloeiro A. Cibrão, utilizando três colunas do Jornal do Commercio, no dia do leilão, 27 de julho, destaca em seu anúncio, que o catálogo das peças era "tudo" o que "servia ao uso deste distincto cavalheiro em sua residência", apresentando em 295 itens os bens a serem leiloados, no próprio endereço que havia servido de moradia ao visconde e à viscondessa.

Com o detalhamento, cuja finalidade era expor o catálogo do leilão, torna-se possível ter uma ideia da casa, da mobília, dos objetos e dos utensílios que faziam parte da moradia dos viscondes, sendo estes oferecidos por aposentos, distribuídos em dois pavimentos. A ordem da exposição e a numeração dos itens por cômodos acompanhavam o percurso arquitetônico da planta da casa, facilitando aos visitantes do leilão apreciar, em sequência, ao longo do roteiro da visita, os itens de 1 a 295.

No primeiro andar, localizavam-se a cozinha e a despensa, o quarto de banho, o quarto de criados, as cocheiras, a sala de jantar e uma salinha [de fumo e café]. No segundo andar, são indicados aposentos designados, sucessivamente, de dormitório, quarto, dormitório nobre, gabinete de estudo e, a seguir, outro quarto, ao qual sucedia um gabinete [biblioteca], uma sala de bilhar, um salão de visitas e a salinha de entrada. Isso induz à ideia de que a planta da casa, a partir da escada, era circular, levando, à esquerda, para a área íntima e, à direita, para a antessala e o salão de visitas, onde estavam os últimos itens numerados no catálogo; provavelmente, porque seriam os finais a serem observados pelos visitantes do leilão.

Nessa perspectiva, o catálogo do leilão da casa dos viscondes constituise em uma rara pista de como, também, estava configurada a moradia, tendo em 
vista que, segundo Malta (2014, p. 575), nessas ocasiões, se “dividia os lotes a serem leiloados pelos espaços em que as peças estavam localizadas e se apresentavam". Todavia, a autora, ao tratar de um leilão realizado em janeiro de 1890, dos bens de Manoel José de Oliveira Figueiredo, que se retirava para a Europa, bem como de outros leilões que nomeavam sucessivamente os ambientes, alerta para o fato de que:

Assim, podemos observar as nomenclaturas em uso, número e tipologia de cômodos, mas sem ter a garantia de se compreender a totalidade dos cômodos. Algumas ausências, como não aparecer nas listas uma sala de jantar, ou reduções, ou a demarcação de poucos cômodos (salão, dormitórios e sala de jantar), indicam que só se registravam os lugares onde peças estavam expostas para venda, podendo existir cômodos vazios, cujos móveis não foram postos em leilão ou estavam agrupados em outros compartimentos da casa (MALTA, 2014, p. 575).

De toda forma, a descrição do leilão da residência dos viscondes de Arcozelo apresenta-se bastante completa em relação aos cômodos citados em outros leilões da época, possibilitando a recomposição da moradia e de seus usos de múltiplas maneiras.

Não obstante, vale enfatizar que o foco do presente estudo é a casa como o lugar de elaboração de escritas íntimas femininas na segunda metade do século XIX, e, notadamente, da escrita da viscondessa de Arcozelo. Deste modo, a análise voltou-se para os locais mais prováveis de sua elaboração, quais sejam o dormitório nobre e o gabinete de estudos, que ficava ao lado do dormitório nobre.

Cabe ressaltar que o gabinete ${ }^{8}$ [biblioteca] do visconde, indicado mais

\footnotetext{
8 De acordo com Hélder Carita (2013, p. 31), durante a primeira metade do século XVIII, aparece uma "nova tipologia de espaço nos interiores da casa nobre designada pelo termo de "gabinete"”. "O gabinete define-se como um espaço de trabalho claramente relacionado com um uso pessoal. Como fenómeno específico do século XVIII, o aparecimento do espaço de gabinete acompanha um processo de maior racionalização dos programas interiores da casa nobre, indiciando, por outro lado, não só a importância da cultura no quotidiano das elites como uma maior dignificação do individuo, que vemos afirmar-se progressivamente, com a
} 
adiante na planta do segundo pavimento, não parece ter sido um local apropriado para a elaboração de escritas femininas, a julgar pela disposição dos móveis e pelos objetos predominantemente masculinos. Contudo, segundo a apresentação do catálogo do leilão, o cômodo designado como "gabinete", e que denominamos como gabinete do visconde, parece ter tido a função de biblioteca, pois possuía uma "bonita bibliotheca de vinhático envidraçada (obra da importante fabrica de Moreira Santos \& C.)”. Essa suposição é corroborada por Carita (2013, p. 32), quando assinala: "podemos inferir que a livraria e o gabinete estavam em íntima ligação”. Dessa forma, parece bem provável ter sido usado também, ocasionalmente, pela viscondessa. Essa suposição pode ser confirmada pelos informes de importação publicados no Jornal do Commercio, nos quais se verifica que o visconde era um importador contumaz de mercadorias, destacando-se, entre estas, livros, como se registra no dia 22 de maio de 1885, data em que ele recebeu, pelo vapor alemão, Baltimore, quatro "caixas de livros". Certamente que esses livros deviam ser colocados nas bibliotecas que mantinha em suas propriedades e, ainda que de uso restrito à viscondessa e às suas noras, alguns deveriam ser permitidos às mulheres da casa.

Voltando ao principal local destinado, particularmente, à viscondessa, o dormitório nobre; ele era assim denominado porque se tratava do quarto do casal, o principal da casa, constatação que se faz, também, pela descrição da mobília e da decoração. No leilão, os itens referentes a esse cômodo não são muitos se comparados aos outros aposentos da casa. Estavam numerados a partir do item 136 e terminavam no item 154, dando a impressão de que algumas peças teriam sido retiradas e levadas para a fazenda onde Maria Isabel permaneceu durante os meses em que o marido esteve fora.

Entre os objetos de decoração que dão início à lista do dormitório nobre, constam artigos essencialmente femininos, de uso pessoal, como uma caixinha forrada de cetim para luvas, um relógio com caixa para viagem, um 
verre d'eaux de cristal esmaltado e dourado, dois frascos e um porta pós de cristal esmaltado e dourado, um porta extratos de cristal e metal, e um terno de cristal para toalete, utensílios que, seguramente, pertenceram à viscondessa, mas devido à sua invisibilidade social, são tratados como objetos pertencentes ao visconde. A seguir, é listada a mobília: uma "riquíssima e esplendida mobília de érable guarnecida de mogno com linda obra de esculptura”, constando de uma "linda" cama com duas faces e enxergão de molas para casados, duas "bonitas" mesas com tampo de mármore para cabeceira, uma "bonita" cúpula forrada de seda com cortinado de filó, um "bem feito" lavatório com mármore, espelho e armário, um toalete com mármore, espelho e tabuleiros, dois "bonitos" guarda-vestidos e gavetões, além de um "elegante" guarda-casacas com porta de espelho, vidro francês, num total de nove peças. Ainda são oferecidos, do mesmo aposento, uma "rica" cômoda de érable, guarnecida de mogno (chifonnier), um colchão de crina, quatro almofadas de paina de seda, uma "rica" guarnição de prata francesa para lavatório, pesando 2,680 gramas (com caixa), quatro "lindas" cadeiras érable, com assento de palhinha, um porta-toalhas de palhinha, um cabide torneado para casacas, uma caixinha de madeira embutida, dois tapetes aveludados para pés de cama, quatro "ricos" jogos de cortinas de guipure com quatro galerias douradas para janelas, e quatro "ricos" reposteiros de reps com galerias douradas.

Os adjetivos usados, em profusão, para designar a mobília e os objetos eram uma estratégia de venda dos anunciantes; mas também refletiam a condição social dos proprietários que os colocavam à venda. Comprar objetos de uma família nobre, como a dos viscondes, garantia a procedência e a autenticidade e, por isso, o detalhamento, por vezes, é substituído apenas pelo adjetivo dado à peça. Michelle Perrot (2011, p. 61), em sua História dos quartos, observa que, 
serve de penteadeira e de guarda-roupa. A escolha dos móveis do quarto cabe ao casal; o marido decide a mobília, com que se gasta mais; a esposa, as cortinas e as tapeçarias. É uma escolha decisiva e para longa duração.

O leilão do dormitório nobre da viscondessa demonstra que sua vida na Corte era cercada de luxo e conforto, o que se comprova não somente pelos objetos da decoração que cercava o seu dia a dia, mas também pela mobília que guardava roupas, casacos, adereços e gêneros pessoais, suficientes para ocuparem muitos guarda-vestidos e gavetões, guarda-casacas e cômodas.

No entanto, ainda que pudesse manter o seu Diário em uma das "bonitas mesas com tampo de mármore para cabeceira" ou escrevê-lo em uma mesinha também usada para "toalete com mármore, espelho e tabuleiros", sentada em uma das quatro cadeiras de palhinha que estavam dispostas no seu quarto, é mais provável que a viscondessa tenha feito uso, para suas escritas pessoais, do gabinete de estudo que ficava imediatamente ao lado do dormitório nobre, considerando a disposição do leilão. Michelle Perrot (2011, p. 90), a propósito da escrita do diário íntimo, assim pondera:

O diário piedoso, tornado íntimo, é escrito à noite. Na solidão do quarto e à luz da luminária. Ele não tolera a presença do outro. Fica escondido em uma gaveta e sua leitura ilícita é tida como uma violação. O quarto compartilhado da união conjugal não lhe é favorável.

O gabinete de estudo, lugar mais presumível de ter sido o cenário de escritas da viscondessa, é apresentado no catálogo do leilão como uma sala com características femininas, diferenciando-se e distanciando-se do gabinete do visconde (descrito mais adiante na planta da casa). Seu detalhamento é iniciado com uma "bonita" pintura a óleo de flores, com moldura dourada, para, em seguida, assinalar uma mesinha redonda denominada de "porta-cartões". Continuando a lista de itens, A. Cibrão descreve a "bonita mobília de fantasia" do gabinete de estudo, constando de oito cadeiras com assento de palhinha, um 
sofá e uma mesinha quadrilonga, totalizando 10 peças.

Além do mobiliário, no gabinete de estudo, reforça a ideia de ser este o local de escrita de Maria Isabel, o fato de haver um "forte piano de mogno, meio armário, com 3 cordas e 7 oitavas, do afamado autor Victor Prealle, e 1 mocho de mogno, com assento de palhinha, para o mesmo", sendo o piano um objeto comum nas salas aristocráticas femininas oitocentistas. Acompanhava ainda essa disposição da sala, "uma estante de mogno para músicas”, dois castiçais de metal para piano, uma charuteira de nogueira para intervalos, duas escarradeiras de porcelana esmaltada, 14 panos de guipure para cadeiras e sofá. Assim como o dormitório nobre, o gabinete de estudo estava coberto por tapetes e cortinas descritos como um tapete aveludado para quatro cadeiras e quatro tapetes aveludados para entrada. Nas janelas, havia quatro "ricos" jogos de cortinas, quatro galerias de reps de cor e um bonito reposteiro de reps de cor, com galeria.

Dos detalhes do mobiliário e da decoração da casa que foi a leilão, o que restou é uma descrição em preto e branco, por vezes, ressaltando a cor da madeira e da palhinha. Entretanto, das outras cores, nada é possível saber; somente supor, pois havia preferências em voga na época: “o verde é muito cotado; o azul é virginal; o vinho, razoável; o cinza, distinto; o creme, básico (tomou conta nos séculos XIX e XX)" (PERROT, 2011, p. 59-60). Seja qual a cor que predominasse, possivelmente deveria fazer um conjunto interessante entre móveis, objetos, tapetes, cortinas, galerias e reposteiros, considerando a preocupação, demonstrada no Diário da viscondessa, de listar suas costuras, seus tecidos e seus aviamentos, o que denota o cuidado em gerir seus bens femininos.

Cinco anos depois, em 1887, é, provavelmente, em um cenário semelhante ao da composição dos móveis e dos objetos leiloados do seu dormitório nobre ou do seu gabinete de estudo, que a viscondessa realiza sua escrita no Diário de Lembranças, em seus dias passados na casa que voltou a possuir na Corte, como indicam seus registros pessoais. 
Todavia, ao analisar o entorno de Maria Isabel, em sua condição de consorte de um dos grandes homens do Império do Brasil, proprietária de casas que possuíam o requinte e a sofisticação possível àquele tempo e contexto, a quem era permitido se desfazer e refazer de seus bens, de acordo com as pretensões do marido, além de ser uma das raras mulheres com acesso às invenções que surgiam e que mudariam o mundo, como o telefone e a luz elétrica, constata-se que sua escrita no Diário é tímida diante da complexidade de circunstâncias que envolviam a sua vida.

Na Gazeta de Notícias de 1879, a propaganda dos trabalhos já executados por F. Rodde, de colocação de campainhas elétricas, listava como comprador o nome do visconde de Arcozelo, entre secretarias, colégios e hotéis. No mesmo periódico, um ano antes, em 10 de novembro de 1878 , em matéria intitulada "Applicação do telephone", se lê:

O Exmo. Sr. Visconde de Arcozello, importante fazendeiro do Paty do Alferes, acaba de introduzir nos seus estabelecimentos agrícolas um dos mais importantes melhoramentos, estabelecendo uma rede de linhas telephonicas entre as suas fazendas e dependências. No dia 6 do corrente foram inauguradas as linhas na presença de várias pessoas gradas do logar, as quaes se mostraram em extremo satisfeitas ao ouvirem a voz chegar claramente da distancia de mais de 10 kilometros, recebendo respostas ás perguntas feitas com a maior certeza e promptidão.

Talvez, por já estar, há uma década, habituada ao uso do telefone, a viscondessa não faça nenhuma referência a esse método de comunicação em seu Diário, sendo apenas possível imaginar que, quando menciona notícias de uma fazenda a outra, tal interlocução tenha sido realizada por meio do telefone, como em $1^{\circ}$ de setembro de 1887 , quando escreve, no mesmo dia, a seguinte sequência:

Às 11 da noite principiou a trovejar, e em seguida veio uma forte chuva de pedras e vento que parecia que acabava o mundo. Foi uma coisa 
medonha. Estragou muito café, deitou todo abaixo. O prejuízo é muito grande. Na Freguesia também choveu bem e caiu algumas pedras. Na P.e [Piedade] choveu, mas não caiu pedra.

Tal suposição torna-se ainda mais evidente quando, em 2 de setembro, ela comenta: "a chuva da noite passada deu muito prejuízo, hoje é que se viu o que ela fez. Principiou-se a plantar milho nas 3 fazendas”. E acrescenta que somente em 3 de setembro foi que "o Castro e Francisquinho foram ver os estragos da chuva de pedras”. Esse é um dos exemplos do Diário de Lembranças, em que notícias precisas são registradas no mesmo dia, em meio a condições climáticas desfavoráveis, sugerindo a possibilidade de utilização do telefone interligando as fazendas, como anunciava a Gazeta de Notícias em 1878.

Os registros sobre as casas da viscondessa de Arcozelo, quando comparados às anotações de sua dona no Diário de Lembranças, evidenciam que estas eram infinitamente mais contidas e modestas do que relatam as fontes existentes sobre as posses e os bens que cercavam o cotidiano daquela mulher nobre. Suas preocupações parecem comedidas diante dos inúmeros afazeres e das funções exercidas pelo visconde, da dimensão e do requinte de suas propriedades e da representação de seus bens nos cenários em que viveu grande parte de sua vida, em suas casas e em suas fazendas. Talvez isso se deva a um traço de sua personalidade, revelado por sua neta, que, ao vê-la pobre, desprovida de toda a riqueza que a acompanhou durante o apogeu de sua existência, tão bem a descreveu: "uma tristeza ver aquela senhora, antes riquíssima, morando naquele casebre. Mas ela era extraordinária: nem uma queixa, nem uma lamúria” (CASTRO, 2004, p. 42).

Assim como não exaltou seu cotidiano, em suas escritas íntimas guardadas em seu Diário de Lembranças, e desvendado, em parte, pelos jornais da época, também não o fez quando ele se transformou completamente nos últimos anos de sua vida. 


\section{CONCLUSÃO: A MESMA LUZ SOBRE PAPÉIS EM TEMPOS DISSONANTES}

De acordo com RISÉRIO (2019, p.137), “mesmo nos sobrados inteiramente ocupados por gente rica, em que escravos moravam e escravos não cessavam de sair era muito difícil alguém conseguir ficar só - e mais difícil ainda cultivar o estar só”. Essa ausência completa de privacidade nas casas oitocentistas, que abrigavam uma grande quantidade de pessoas e que exibiam um permanente transitar de serviçais, era ainda mais afeita às mulheres, mantidas em constante vigilância.

Sob tal condição, a escrita feminina de um diário tornava-se uma prática que precisava dispor de consentimento e de tempo para ser exercida, mesmo que se tratasse tão-somente de anotações cotidianas sem nenhum registro mais comprometedor. Ainda assim, a casa que abrigava mulheres escritoras precisava tornar-se um ambiente propício para esse fim, em que pese Bollmann (2011b, p.10), citando Virgínia Woolf, sinalizar que, ao longo da história, "nenhuma ocupação feminina era bastante importante para não poder ser interrompida a qualquer momento”.

Às mulheres, cabiam outras prioridades para além da ocupação com suas escritas pessoais, que só podiam ser realizadas quando suas "obrigações”, próprias da condição feminina, já estivessem cumpridas. Portanto, escrever um diário era quase uma "premiação" concedida àquelas que, por "bom comportamento" - e já tendo exercido o seu papel na casa -, podiam sentar-se para se dedicar à escrita elaborada a partir de seus pensamentos íntimos.

Nessa perspectiva, a casa oitocentista, que era o cenário da escrita de mulheres em seus aposentos mais herméticos, era também o espaço que limitava a privacidade, que exigia delas o desempenho de funções complexas e que abrigava todos os elementos que guardavam a representação do que era apropriado e permitido ao gênero feminino. Diante de tantas restrições, como analisa Muaze (2008, p.140) em relação a uma contemporânea de Maria Isabel, "mesmo em suas reflexões mais íntimas, a vida familiar sobressaía às 
impressões pessoais. Aquela mulher não conseguia fugir da dimensão familiar". O mesmo acontecia com a viscondessa de Arcozelo.

O Diário da viscondessa, embora evidencie alguns vestígios para a recomposição do cenário em que está sendo escrito, especialmente se confrontado ao que restou de informações documentais, inventários, notícias de jornais, edificações, ainda assim, é somente uma fonte, que indagada em relação às condições dos espaços em que era produzida, pode oferecer algumas respostas. De verdadeiro e inquestionável, somente a luz que entra pela fresta aberta das janelas nas reconstituições das casas e nas instalações das fazendas onde ela viveu. Essa, sim, é a mesma luz que, certamente, pousou sobre o Diário, naquele longínquo 1887.

\section{REFERÊNCIAS}

BOLLMANN, Stefan. Las mujeres que leen son peligrosas. Madrid-ES: Maeva Ediciones, 2011a.

BOLLMANN, Stefan. Las mujeres que escriben también son peligrosas. Madrid-ES: Maeva Ediciones, 2011b.

BRYNSON, Bill. Em casa: uma breve história da vida doméstica. São Paulo: Companhia das Letras, 2011.

CARITA, Hélder. Do scriptorium ao gabinete e à casa da livraria. Espaços da escrita nos interiores da casa nobre em Portugal. In: MALTA, Marize; MENDOC_A, Isabel M.G. (Org.). Casas senhoriais Rio-Lisboa e seus interiores. Rio de Janeiro: Universidade Federal do Rio de Janeiro, 2013, p. 25-49.

CASTRO, Maria Werneck. No tempo dos barões: histórias do apogeu e decadência de uma família fluminense no ciclo do café. Rio de Janeiro: Bem-Te-Vi, 2004.

GAGLIARDO, Vinicius Cranek. Uma Paris dos trópicos?: Perspectivas da europeização do Rio de Janeiro oitocentista. São Paulo: Alameda, 2014.

GAZETA DE NOTÍCIAS, 10 de novembro de 1878, p.3. 
GAZETA DE NOTÍCIAS, 07 de setembro de 1879, p.5.

GAZETA DE NOTÍCIAS, o5 de janeiro de 1887, p.1.

JORNAL DO COMMERCIO, 25 de outubro de 1879, p.2.

JORNAL DO COMMERCIO, 16 de junho de 1883, p.3.

JORNAL DO COMMERCIO, 27 de junho de 1883, p.4.

JORNAL DO COMMERCIO, 22 de maio de 1885, p.4.

JORNAL DO COMMERCIO, 27 de dezembro de 1887, p.2.

JORNAL DO COMMERCIO, 12 de fevereiro de 189o, p.3.

JORNAL DO COMMERCIO, o8 de abril de 1890, p.2.

LEJEUNE, Philippe. Diários de garotas francesas no século XIX: constituição e transgressão de um gênero literário. Cadernos Pagu, Campinas, n. 8/9, 1997, p. 99-114.Disponível em:

www.bibliotecadigital.unicamp.br/document/?down=51147. Acesso em: 14 out. 2019.

LORIGA, Sabrina. O pequeno X: da biografia à história. Belo Horizonte: Autêntica Editora, 2011.

MALTA, Marize. Sumptuoso leilão de ricos móveis... Um estudo sobre o mobiliário das casas senhoriais oitocentistas no Rio de Janeiro por meio de leilões. In: MENDONÇA, Isabel M. G.; CARITA, Hélder; MALTA, Marize. (Org.) A casa senhorial em Lisboa e no Rio de Janeiro: anatomia dos interiores. Lisboa, Rio de Janeiro: Universidade Nova de Lisboa, Universidade Federal do Rio de Janeiro, 2014, p. 562-580.

MARTINS, Ana Luiza. História do café. São Paulo: Contexto, 2009.

MAUAD, Ana Maria; MUAZE, Mariana. A escrita da intimidade: história e memória no diário da viscondessa de Arcozelo. In: GOMES, Angela de Castro (Org.). Escrita de si, escrita da história. Rio de Janeiro: Editora FGV, 2004, p. 197-228.

MELLO, Evaldo Cabral de. O fim das casas-grandes. In: ALENCASTRO, Luiz Felipe de (Org.). História da vida privada no Brasil: Império, a corte e a modernidade nacional. São Paulo: Companhia de Bolso, 2019, p. 302-349.

MUAZE, Mariana. As memórias da viscondessa: família e poder no Brasil Império. Rio de Janeiro: Jorge Zahar Editora, 2008. 
SANTOS, Ana Lúcia Vieira dos. Formas de morar no Rio de Janeiro do século XIX: espaço interior e representação social. In: MENDONÇA, Isabel M. G.; CARITA, Hélder; MALTA, Marize. (Org.) A casa senhorial em Lisboa e no Rio de Janeiro: anatomia dos interiores. Lisboa, Rio de Janeiro: Universidade Nova de Lisboa, Universidade Federal do Rio de Janeiro, 2014, p. 208-223.

SCHETTINO, Patrícia Thomé Junqueira; LEMOS, Celina Borges. “O Palacete Carioca”. Estudo sobre a relação entre as transformações da arquitetura residencial da elite e a evolução do papel social feminino no final do século XIX e início do século XX no Rio de Janeiro. In: MENDONÇA, Isabel M. G.; CARITA, Hélder; MALTA, Marize. (Org.) A casa senhorial em Lisboa e no Rio de Janeiro: anatomia dos interiores. Lisboa, Rio de Janeiro: Universidade Nova de Lisboa, Universidade Federal do Rio de Janeiro, 2014, p. 318-337.

PERROT, Michelle. As mulheres ou os silêncios da história. Bauru: EDUSC, 2005.

PERROT, Michelle. História dos quartos. São Paulo: Paz e Terra, 2011.

RISÉRIO, Antonio. A casa no Brasil. Rio de Janeiro: Topbooks, 2019.

VASCONCELOS, Maria Celi Chaves. A escrita cotidiana no Diário de Lembranças da Viscondessa de Arcozelo: fragmentos (auto) biográficos de um egodocumento. In: VASCONCELOS, Maria Celi Chaves; CORDEIRO, Verbena Maria Rocha; VICENTINI, Paula Perin (Org.). (Auto) biografia, literatura e história. Curitiba: CRV, 2014, p. 95-114.

VASCONCELOS, Maria Celi Chaves. Uma mulher educada no oitocentos: a escrita feminina no Diário da Viscondessa de Arcozelo. Revista Educação em Questão, UFRN, Natal, v.53, n.39, 2015, p.104-131.

VISCONDESSA DE ARCOZELO. Diário de Lembranças da Viscondessa de Arcozelo, ano de 1887. Museu Imperial em Petrópolis. Códice DMI-15.

MARIA CELI CHAVES VASCONCELOS é pós-doutora em Educação pela Universidade do Minho. Doutora em Educação pela Pontifícia Universidade Católica do Rio de Janeiro (PUC-Rio). Professora Titular da Universidade do Estado do Rio de Janeiro (UERJ), atuando no Programa de Pós-Graduação em 
Educação (Proped). Bolsista de Produtividade do Conselho Nacional de Desenvolvimento Científico e Tecnológico (CNPq). Bolsista do Programa Prociência (Uerj). Cientista do Nosso Estado/Fundação de Amparo à Pesquisa do Estado do Rio de Janeiro (Faperj). Presidente da Câmara Conjunta de Educação Profissional e Superior do Conselho Estadual de Educação do Rio de Janeiro $(C E E / R J)$. Pesquisadora na área de História da Educação e Políticas Educacionais, com ênfase na educação doméstica no Brasil oitocentista e criação/consolidação dos sistemas educacionais, além da educação na casa e suas implicações na atualidade. Líder do Grupo de Pesquisa "História e memória das políticas educacionais no território fluminense" - Uerj/CNPq. Autora de livros, capítulos e artigos científicos; e organizadora de coletâneas resultantes de trabalhos de pesquisa.

E-mail: maria2.celi@gmail.com

(b) http://orcid.org/0000-0002-3624-4854

Recebido em: 23 de outubro de 2019

Aprovado em: 10 de janeiro de 2020

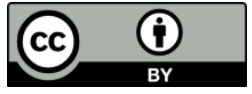

História da Educação - RHE

Associação Sul-Rio-Grandense de Pesquisadores em História da Educação - Asphe

Artigo de acesso aberto distribuído nos termos de licença Creative Commons. 